\title{
Halfhearted Action and Control
}

\author{
JOSHUA SHEPHERD
}

\begin{abstract}
Some of the things we do intentionally we do halfheartedly. I develop and defend an account of halfheartedness with respect to action on which one is halfhearted with respect to an action A if one's overall motivation to A is weak. This requires getting clear on what it is to have some level of overall motivation with respect to an action, and on what it means to say one's overall motivation is weak or strong. After developing this account, I defend the claim that one key functional expression of halfhearted action is the possession of impaired control over the action in question. Finally, I elucidate a puzzle that sometimes arises with respect to halfhearted action. The puzzle arises when an agent's commitment in acting conflicts with an agent's acceptance of poor performance.
\end{abstract}

\section{Introduction}

Some of the things we do intentionally we do halfheartedly. It is 3 p.m. You are grading papers, as you must. But you don't really want to. It is sunny, and you want to be in the park. Your legs hurt, and you want to take a walk. You await an important e-mail, and you want to check for it. You both want to do something else, and you do not want to do the thing you are doing. ${ }^{1}$ You grade the papers intentionally. But you also grade them halfheartedly.

In this paper I focus on the nature and structure of halfhearted action. I have at least three reasons for doing so. First, halfhearted action is a common feature of our lives as human agents. That is, a significant number of our intentional actions are halfhearted to at least some degree. Yet, one finds very little discussion of halfheartedness, at least as I understand the notion. The discussion I offer below helps remedy this.

Second, for reasons I elucidate below, halfhearted action is importantly re-

1. Compare G.F. Schueler, who notes that there is a "perfectly good" sense of desire according to which "there is nothing at all problematic or mysterious about people doing things that have no desire to do, things they don't want to do at all. I would say, for instance, that I had no desire to attend a meeting at my son's school the other evening. I would much rather have stayed home and read. But I did attend the meeting because I believed I had a responsibility to do so ..." (1995: 29). 
lated to an agent's motivational strength (or lack thereof). The nature of motivational strength and weakness is a longstanding concern for the philosophy of mind and action (e.g., Clark 1994; Mele 1998; Gert 2005), and a focus on halfhearted action illuminates under-explored aspects of motivation in action. In particular, the discussion below highlights an interesting relationship between motivational weakness and attentional control.

Third, as I explain below, a focus on halfhearted action reveals an interesting kind of conflict within agency, between an agent's commitment in acting and an agent's acceptance of poor performance. This conflict raises a kind of explanatory puzzle. Confrontation of the puzzle promises to advance knowledge of the structure of human agency.

Before beginning in earnest, the following remark may prevent unnecessary confusion. Although I focus on the nature and structure of halfhearted action, in what follows I do not offer anything like a conceptual analysis of 'halfhearted action.' Indeed, attempting to do so would, in my view, be foolhardy. Halfhearted action is a messy but philosophically interesting phenomenon that has as much to do with contingent features of human motivation and action as it does our concepts of motivation and action. So what I offer below is, I hope, a philosophically illuminating discussion and explanation of the structure of halfhearted action, rather than anything like necessary and sufficient conditions for halfhearted action.

From here things proceed as follows. In Section 2 I lay out an account of halfheartedness in terms of weak overall motivation to A. In Section 3 I further develop and defend a key claim of the account, namely, that halfheartedness in action impairs the degree of control an agent possesses over that action. In Section 4 I elucidate the aforementioned puzzle involving a conflict between commitment and acceptance, and distinguish it from related puzzles to do with weakness of will and synchronic self-control.

\section{Halfhearted Action and Weak Motivation}

As I will understand it, halfheartedness with respect to action is a motivational phenomenon. That is, an agent is halfhearted with respect to an action A in virtue of weak overall motivation to A.

Readers versed in the philosophy of action might assume that my notion of halfheartedness is related in some way to Harry Frankfurt's well-known notion of wholeheartedness (Frankfurt 1998). It is worth noting, then, that there is in fact no direct relationship. For Frankfurt, wholeheartedness is not a matter of motivational strength, but of coherence amongst one's higher-order motivational states. One is wholehearted with respect to a motivational state $\mathrm{M}$ if one 
identifies with $\mathrm{M}$ by possessing a higher-order desire to be motivated by $\mathrm{M}$, and this higher-order desire is in some sense unopposed. As Frankfurt puts it, "When a person identifies himself decisively with one of his first-order desires, this commitment 'resounds' throughout the potentially endless array of higher orders" (1998: 21). As Frankfurt conceptualizes wholeheartedness, then, its opposite is not halfheartedness, but rather what he calls ambivalence-the presence of conflicts among or questions about the pertinence of one's higher-order motivational states (or, in Frankfurt's parlance, one's volitions).

Frankfurtian ambivalence may contribute to motivational weakness and thus halfhearted action. But conflicts amongst higher-order motivational states are only one potential contributor to motivational weakness. The notion of motivational weakness at issue here is broader, and ultimately distinct. That is, one can be wholehearted regarding some motivational state to A while A-ing halfheartedly. This is possible because motivational weakness is multiply realizable, and sometimes one's motivation wanes in spite of the presence of higher-order desires and the absence of motivational conflicts.

In order to understand what it is to A with weak overall motivation to A, we need to know something about the broader category of motivational strength (or motivational level). Some action theorists have charged that the notion of motivational strength is too obscure or vacuous to be useful (Thalberg 1985). Fortunately, this is not the case (see, e.g., Clark 1994; Mele 1998; Gert 2005). A discussion of the motivational strength of a particular motivational attitude illustrates this, and serves as a building block.

Alfred Mele (1998; 2003) offers an explication of the motivational strength of a particular attitude: what he calls an action-desire. This is a proximal or present-directed desire to perform an action, or a desire to A now. Mele's view is that the motivational strength of an action-desire is grounded in a subset of its dispositional properties, namely, those responsible for causing the agent to A. These properties are in turn grounded in their causal bases. ${ }^{2}$ In the case of action-desires, Mele assumes (very plausibly) that these causal bases are physical bases associated with motivational aspects of the nervous system. This allows an analogy with other straightforwardly dispositional systems.

It may reasonably be suggested that we can conceive of the relative strength of a human agent's action-desires at a given time as analogous ... to the relative fragility of the vases stored in my son's kitchen and to the relative elasticity of the various rubber bands in my desk-drawer: there is a physical basis in each case, and comparative truths about the fragil-

2. On the notion of a disposition's causal basis, see Prior, Pargetter, and Jackson (1982), McKitrick (2003). 
ity, the elasticity, and the motivational strength of the relevant items are grounded in differences in the physical bases. (Mele 2003: 173)

Understanding motivational strength in these terms affords a way to make sense of comparative claims about the strength of, e.g., competing desires. As Mele has it, to claim that one action-desire is stronger than another at a time is, in part, to claim that

if, at $t$, I were to proceed to make an attempt appropriate to any of my pertinent untrumped proximal action-desires because of relevant properties of the desire's realizer, I would proceed to make one appropriate to my desire to A (or it is more probable that I would make one appropriate to my desire to A than that I would make any other attempt). (2003: 173)

In saying this much regarding a particular attitude's motivational strength, Mele is explicitly bracketing a number of features that might contribute to overall motivation at a time: motivational biases, pre-existing intentions, motivationally contributory states, and so on. The move from claims about the motivational strength of one kind of motivational attitude to claims about overall motivational strength adds considerable complexity. The dispositional basis of one's overall motivation to A will consist of the dispositional properties of a range of accessible motivational mental states and processes relevant to one's A-ing. These may include emotions (Scarantino \& Neilsen 2015), desires (Mele 2003), intentions (Mele 1992), as well as modificational work done by relevant beliefs, perceptual states, states of imagination, and more.

Accounting for all of the types of motivational states and the ways they interact would be a massive task. It will suffice here to note that we have good reason to think agents possess levels of motivation regarding action options, so that we can coherently talk of (strong or weak) overall motivation to A. Consider how I began this paper-by speaking of a familiar instance of weak motivation in action (philosophers may have already blocked it from memory: it involved grading papers). The familiarity of such instances is often marked by folk psychological ways of referring to weak motivation. Of some actions we say 'My heart wasn't in it,' 'That was boring,' or perhaps 'I'm just going through the motions.' These ways make reference to signs of motivational weakness, of which there are several - the phenomenal intensity of one's motivational states, various other bodily cues that tend to generate beliefs about one's motivational levels, the kinds of thoughts generated by reflection on the satisfaction of intentions. None of these may constitute motivational weakness. Plausibly, one's motivational levels are constituted by sets of dispositions whose bases involve physical features of one's body, including the state of (perhaps) things like one's muscles 
and respiratory system, and certainly including the state of elements of the nervous system, including arousal levels and features of the reward system. This is not a rigorous account of the constitution of motivation. The present point is that we have reason to think that one's overall motivational level with respect to an action is a psychologically real phenomenon, and that we are able to form veridical beliefs about our own motivational levels with respect to prospective and ongoing actions.

One can accept the psychological reality of motivational levels with respect to an action without clearly understanding what it is for overall motivation to A to be weak. When one claims that one's overall motivation to A is weak, one deploys a gradable predicate. On the standard semantics (see Kennedy 2004 for a review), gradable predicates map the objects they modify onto scales. Scales are constructed out of three parameters: degrees (or measurement values), a dimension of measurement, and an ordering relation. So, for example, when comparing the planets in our solar system, one might deploy a scale whose dimension is size, whose degrees involve some unit of size measurement, and whose ordering moves from smaller to larger.

In this way, to say that one's overall level of motivation to $\mathrm{A}$ is weak or strong requires a degreed scale (we can leave the units of measurement unspecified) whose dimension of measurement is strength. Further, it requires one to place the attributed motivational level somewhere on the scale. This last move is non-trivial. In order to say that motivation is weak (or weaker than), one needs to understand how the degrees of motivational strength are ordered. In order to have this understanding, one needs to specify two factors. First, one needs a standard of comparison. Second, one needs a class of comparison across which to apply the standard.

Let us focus on the class of comparison first. Due to the fact that motivational levels fluctuate over time, and may differ between agents with different physical constitutions, different psychological conditions, and so on, some specificity is required in marking out the relevant class. In this connection, it is worth admitting up front that regarding motivational strength, there may be several explanatorily useful ways of constructing a class of comparison (see the following footnote for examples $\left.{ }^{3}\right)$. As is the case with many other gradable adjectives (tall, pretty, silly), one's level of motivation with respect to A-ing may be very

3. One might contrast an agent's motivational level to A at a time with that agent's normal level of motivation to A. This might be useful if one wants to explain differences in performance in certain conditions (i.e., those that deviate from normalcy). Second, one might contrast an agent's motivational level to A at a time with an agent's motivational level to B at that same time. This might be useful if one wishes to ask whether agents always (or necessarily) do what they are most motivated to do at a time. Third, one might contrast an agent's motivational level to A at a time with the normal motivational level of some background class of similarly constituted agents (say, agents with similar physical constitutions and similar levels of skill). The science of motivation 
weak when measured against one class, and not weak when measured against another. With that said, this discussion of motivational strength aims at an explication of halfheartedness with respect to action. The notion of halfheartedness at least suggests a focus on an agent's particular levels of motivation regarding particular actions-halfheartedness with respect to an action might be thought to be low overall motivation for that agent with respect to that action, that actiontype across some class of counterfactual circumstances, or even with respect to similar action-types across counterfactual circumstances. Even here, however, there may be different useful ways of constructing a class of comparison. I will mention two. First, consider the class of motivational levels an agent may possess with respect to a particular action-type across a wide range of physical conditions. If an agent's motivation to A at a time is on the low end for that class, it may be fair to say that the agent is halfhearted with respect to that action. For the agent is capable of possessing greater motivation to $\mathrm{A}$, and in most other physical conditions she would possess more. Second, consider the class of motivational levels an agent typically possesses with respect to all the action-types of which she is capable. There will be action-types that fall on the low end of this scale (maybe this is washing the dishes, or changing diapers, or firing an employee, or whatever). As such, this comparison class gives us a way of specifying how an agent may be regularly halfhearted with respect to some action-type. For that agent, the action-type in question will be typically accompanied by comparatively weak motivation.

I turn from the class of comparison to the standard of comparison. This is what allows one to say why some level of motivation qualifies as weak or strong. Here one has to be careful. One's motivational level regarding some specific action is a complex set of dispositions. To order this set of dispositions in terms of weakness and strength one should say something about how the dispositions manifest. This requires one to say something about what manifestation looks like. Regarding the fragility of a vase, this is fairly easy: the disposition manifests when the vase breaks (so long as there is no funny business). The dispositions that constitute one's motivational level to A are more complex. Indeed, motivational states and processes have several kinds of causal impact. They may commonly cause one to token various experiential states, to token various facial expressions, or whatever. But we are presently concerned with a specific set of causal impacts, and therefore a specific set of motivational dispositions. Consider levels of fragility and elasticity. These are dispositional notions that implicitly circumscribe the functions (e.g., breaking, stretching) that permit ordering relationships. In our case, we are focused on the levels of one's motivation to act. As

arguably depends upon the specification of some such class for the development of controlled studies. 
such, we circumscribe the functions to features of acting. I doubt I can cover logical space here, but a good place to start is with what I (and others) regard as the chief functional roles of motivational states and processes for action. These are the initiation, sustaining, and guidance of action. ${ }^{4}$ These three functional roles give one three different ways to set up an ordering relation. One's overall motivation to A might be weak with respect to A's initiation, $\mathrm{A}^{\prime}$ s continuance (up to some arbitrary point, or up to completion), or A's guidance. ${ }^{5}$

I will have relatively little to say about the first two functions (which does not imply that they are uninteresting). Briefly, however, the discussion above indicates one way of thinking about how weak motivation may manifest with respect to initiation and sustenance of action. Recall that Mele graded the strength of action-desires in terms of their propensity to cause appropriate attempts. We might think of overall motivation to initiate A-ing in similar terms. That is, we might say that some agent J's overall motivation to initiate A-ing should be considered stronger at time $\mathrm{t}_{1}$ than at time $\mathrm{t} 2 \mathrm{if}$, all else being equal, $\mathrm{J}$ is more likely to initiate A-ing at $\mathrm{t} 1$. And we might say that J's overall motivation to initiate A-ing at $t_{1}$ is weak if it falls below some threshold on a scale ordered with respect to some well-constructed contrast class-e.g., the class of times at which the agent possesses some non-zero level of motivation to A. This gives us a way of making sense of the intuitive thought that agents weakly motivated to A often do not initiate A-ing. ${ }^{6}$ A similar kind of account could be transferred to the function of sustaining an already initiated A-ing to completion.

My focus in what follows concerns the relation of weak overall motivation to the guidance of action. For, even though it is true that agents with overall weak motivation to A are less likely to A or to continue A-ing than agents with stronger levels of motivation, we do sometimes intentionally A even while weakly motivated to do so. In such cases, halfheartedness with respect to an action leads to halfhearted action. Can we make sense of the role of weak overall motivation to A for A's guidance? The situation here is more complex than that of action initiation or the sustaining of action to completion. Action guidance is a process

4. Paradigmatically, these roles are given to intentions and action-desires, though related states such as emotions may play these roles as well (see Scarantino \& Nielsen 2015). In this connection, it is worth mentioning that these are not the only functional roles one might consider. An additional, and probably important functional role for motivation in action concerns the learning processes that contribute to, e.g., skill acquisition (Kanfer \& Ackerman 1989; Wulf, Shea, \& Lewthwaite : 2010).

5. Of course one might specify motivational weakness with respect to more fine-grained components of action as well. After all, it is sometimes the case that one is strongly motivated to perform some complex action (e.g., eating a meal) while being only weakly motivated to perform some sub-action that is a part of it (e.g., eating the broccoli that is necessary to receive the carrot cake).

6. For a congenial and far-reaching discussion of the gradability of dispositions more generally, see Vetter (2014). 
with significant internal structure. As such there may be many appropriate ways for the dispositions that undergird action execution to manifest. If we want to reflect upon the impact of motivational weakness here, we have to aim at the appropriate level of abstraction. Towards this end, I suggest that an illuminating way of grouping the dispositions together is in terms of their contribution to the potential quality of an action's guidance - that is, to the degree of control an agent possesses over the action in question. Put explicitly, at an abstract level one functional expression of halfhearted action is the possession of less control over the action in question.

In the next section I develop and defend this idea.

\section{Halfhearted Action and Control}

In claiming that one functional expression of halfhearted action is the possession of less control, I do not claim that to act halfheartedly is just to act with less control. There are more ways than one to possess a low degree of control over one's action. We are focusing on action that is poorly controlled in virtue of overall motivational weakness. So this is action poorly controlled in virtue of properties of the motivational system.

Nor would I claim that to act halfheartedly is just to act with less control in virtue of properties of the motivational system. I want to leave it open that there are multiple ways for the motivational system to hijack action execution. For example, it might turn out to be the case that human agents can be too strongly motivated, and that over-motivation impairs action control as well.

The above claim connecting halfhearted action and diminished control depends on a substantive belief about control-that there is a clear sense in which agents possess more or less control over various actions. Is there?

I think so. To explain why, I draw on previous work of my own regarding the nature of control (see Shepherd 2014). On my account, the possession of control over an action is (roughly) the possession of an ability or set of abilities to bring behavior to match the content of some pertinent motivational state, and to do so with flexible repeatability. The intuition behind repeatability is that possession of the brute causal ability to make something happen does not amount to control. Since I have the ability to strike a golf ball such that it travels 230 yards in some direction, I have the ability to strike a golf ball such that it flies 230 yards and falls into a small hole. But I lack the ability to strike a ball in any particular direction with any repeatability. So I lack the ability to repeatedly hit a hole-in-one. The intuition behind flexibility is that repeatability in exactly the same circumstances is cheap. What we want to see is the ability to repeatedly perform some action across circumstances that differ in some theoretically interesting way. 
Consider how this would work in cases of halfhearted action. Let us stick with golf. We fix the nature of the action-type, and two sets of counterfactual circumstances. The action-type could be delineated by an intention to swing in a certain way while focusing on the ball, and thereby to hit the ball to within some distance of the hole. The sets of circumstances could be 1000 instances with similar lighting and wind, during which motivation is relatively weak, and 1000 instances with exactly similar lighting and wind, during which motivation is not relatively weak. The agent's performance across the sets would give us two success-rates for the agent concerning distances to the hole, swinging in the way intended, and focusing on the ball for the parts of the swing intended. We would thus have a range of information regarding the agent's degree of control with respect to the action of hitting the ball when motivation is weak or not.7 If the agent possesses less control over behavior in the second set of circumstances - if her performance is poorer, i.e., if she approximates the content of her intention to a lower degree across the set of circumstances - then we can blame the motivational deficit for the decrement in control (see Shepherd 2014: Section 3).

Is there any evidence for this picture of the impact of weak motivation on action execution? In fact multiple lines of research indicate that conditions plausibly assumed to weaken motivation compromise action control, primarily by impacting the normal functioning of attention. I cannot review all of the relevant work here. My aim is to make the main contours clear and convincing.

Consider, then, research that focuses on the relationship between motivation and cognitive control via vigilance tasks, actions that require sustained attention, actions that require 'task-switching' between cognitive strategies, and actions that follow a 'depleting' task. At an abstract level, there is a growing consensus in this area that shifts in an agent's motivation are a crucial part of the explanation for patterns of performance in these kinds of tasks. In general, agents get progressively worse at these kinds of tasks the longer they perform them (in one sitting). However, changing the motivational structure of these actions-e.g., by increasing the reward agents receive for performing them well-attenuates and sometimes eliminates poor performance in otherwise similar circumstances.

For example, recent work indicates that increasing motivation by degree by increasing monetary incentives enhances the orienting and reorienting functions of exogenous spatial attention by degree (Engelmann \& Pessoa 2014), as well as that an agent's expectation of reward enhances "attentional concentration" to task-relevant as opposed to task-irrelevant information (Wei, Wang, \& Liyan 2015). When motivation is sapped, attention is prone to wander. Disengagement of attention from the present action (sometimes called 'goal neglect,' sometimes

7. This account actually affords a number of measures of control, since we can specify a level of match between actual behavior and intended action, and examine the agent's success-rate at reaching that level. 
studied under the moniker 'mind wandering') leads to decrements in performance (Smallwood, Beach, Schooler \& Handy 2008; McVay \& Kane 2009). This work suggests that at an abstract level, performance decrements are due proximally to attention, and somewhat more distally to weak motivation.

Regarding the specifics, a number of proposals remain afloat. Kurzban, Duckworth, Kable, and Myers (2013) offer a model whereby sub-personal estimates of a current action's utility compete with estimates of the utility of alternative actions. If the current action's utility dips relative to the next best action, agents experience a sense of effort in the current task, and this sense of effort motivates the agent to shift processing resources (e.g., attention) in some way to the other action (or to consideration of it: the details are vague). The shift of processing resources, according to Kurzban et al., is proximally responsible for performance decrements.

In several papers, Maarten Boksem and Mattie Tops offer an alternative model (Boksem \& Tops 2008; Tops \& Boksem 2011; Tops, Boksem, \& Koole 2013). On their model, experiences of effort-as well as experiences of fatigue, resistance, and discomfort-are more closely tied to the sub-personal monitoring of physiological resources and costs associated with the present action. The monitoring of resources and costs - which can be influenced by perception of additional reward (Boksem \& Tops 2008) - does not always motivate allocation of processing resources to alternative tasks. Instead, outputs of this process "may stimulate disengagement, inactivity, and recuperation when perceived resources . . . are low" (Tops, Boksem, \& Koole 2013: 704).

A third model emphasizes experiences of boredom and their impact upon attention. According to Eastwood, Frischen, Fenske, and Smilek (2012), experiences of boredom arise due to lack of satisfaction in current activity, and cause shifts of attention away from the present action (see also Bench \& Lench 2013). These boredom-induced shifts of attention are often responsible for performance decrements.

These are three proposals. There are many more (see, e.g., the commentaries in Kurzban et al. 2013). They are not necessarily in competition. The kinds of assessments of an action as boring or effortful, or assessments of oneself as fatigued, at issue in these studies, all plausibly contribute to (and may in some cases partially constitute) an agent's weakened motivation. So while disagreement remains about the specific ways motivation engages attention, about the best ways to characterize motivational shifts, about the computational processes that underlie attentional engagement and disengagement, about the role of various experiences (effort, boredom, fatigue) in the process, and about the mechanisms whereby attentional disengagement leads to performance decrements, there is significant consensus that at a general level weak motivation impairs performance by leading to attentional distraction. 
Notice a prediction this model makes. If attention is the more proximal culprit for action control decrements, one should predict that improving attention should lead to improved performance in spite of compromised motivation.

It appears that this is the case. In a study by Mrazek, Franklin, Phillips, Baird, and Schooler (2013), participants were subjected to two weeks of a nutrition class (the control condition) or to two weeks (eight 45-minute sessions) of training in "focused-attention meditation" (2013: 2). Before and after these classes, participants completed a working memory control task as well as a verbal reasoning task. During the verbal reasoning task, mind wandering was tested via interspersed thought sampling. During the working memory control task, mind wandering was tested via a retrospective report. Both measures aim to discover "the extent to which [participant] attention was focused on the task or on unrelated concerns" (2013: 3).

Mrazek et al. found that compared to the control condition, the attentional training condition significantly improved performance on both tasks, and significantly reduced mind wandering during both tasks. While it is possible that the attentional training condition enhanced motivation for performing the working memory control or verbal reasoning tasks, it is more plausible that what we have here is an effect on attention irrespective of motivation. Through attentional enhancement, the normal effect of motivation on performance is blocked.

Empirical work indicates, then, that halfhearted action-here understood, roughly, as overall motivation to A that is significantly weaker than an agent's typical motivation to $\mathrm{A}-$ is action under less control. Of course, this work significantly underdetermines the various ways weakened motivation may do so. The route suggested above runs via attention, but for all the science shows a number of alternate routes remain possible.

Two referees have offered a good objection. It involves appeal to easy actions. Surely, the thought goes, there are some actions that we can perform more or less perfectly no matter our level of motivation to do so. Are we to believe that even extremely weak motivation could impair control over arm raising or taking a step? If not, one might worry that impaired control is not a key functional signature of halfhearted action.

I see two lines of response. The first is the most concessionary. On it, I grant the in-principle possibility of actions one can perform perfectly every time no matter how weak one's motivation. Granting this carves action-types into two classes: those impacted by weak motivation and those not impacted by weak motivation. This latter class would be interesting. If agents could come to know, even roughly, which actions fell into this class, they would then be able to rely on these actions for purposes of planning. Even more than an agent's basic actions, this would be a class on which agents could rely.

However, I do not prefer this line of response, at least regarding human 
agents. Although it may seem like some actions are extremely easy, and a lack of motivation could not impact them, action slips regarding very easy actions take place all the time. Action slips do not always result from low motivation, of course, but the fact that we are not perfect regarding very easy actions should reduce the force of the present objection. In this connection, consider that many of the vigilance tasks mentioned above involve very simple actions, e.g., noticing something on a screen and pressing a key. Although this may be surprising, it appears that even for very simple actions if motivation dips enough, mistakes can be made.

The second line of response maintains that weak motivation will, in some cases, impair control only slightly. Plausibly, there will be action-types for which extremely weak motivation will nonetheless impair control to a minor degree, as well as action-types for which barely weak motivation will impair control to a major degree. The claim is just that one key functional upshot of halfhearted action is possession of less control. On this line of response, we can still maintain that an interesting class of actions exists that is relatively impervious to weak motivation.

A second objection presses me to be more modest. On this objection, I should scale back the claim about halfhearted action, instead maintaining that a key functional signature is not impaired control, but distracted attention. After all, this is the core of what the empirical work reviewed above shows.

I think there is something right about this objection. Ultimately, in order to develop a functional understanding of halfheartedness, we need to map the key functional upshots of overall weak motivation to A. One of these looks to be an impact on attention. Having said this, however, I think it is appropriate to place this under the broader heading of action guidance. The reason is that attention is a critical part of action guidance, at least for most action-types. Further, there may well be other ways weak motivation impairs control-as I said above, for all the science shows impaired attentional control is just one way action control is impaired.

\section{A Puzzle about Halfhearted Action}

I have offered an account of halfheartedness with respect to action in terms of weak overall motivation to $\mathrm{A}$. This required getting clearer about the notion of overall motivational strength with respect to an action, and of what it might mean to say that motivation is weak or not. If the discussion above has been successful, then, it represents philosophical progress regarding a familiar but underexplored feature of human agency. But this is not the only reason a philosopher might care about halfhearted action. For halfhearted action sometimes generates a conflict within the agent. 
Before elucidating the conflict and puzzle, it may help to place it within a broader context. Towards that end, consider two better-known puzzles. The puzzle of weakness of will concerns a conflict between an agent's judgment about what it is best to do all things considered and what an agent in fact does. If an agent (intentionally, freely) A-s in spite of judging it best all things considered to B, we say she has acted akratically - she has demonstrated weakness of will. The puzzle is how this could be possible. Some philosophers deny the possibility of akratic action (e.g., Hare 1952); some philosophers defend the possibility (e.g., Mele 1987). One interesting feature of the puzzle is that it notes a potential point of conflict within agents: solving the puzzle requires making theoretical decisions about the structure of the mind and the relationships between the conflicting elements.

The same is true of the puzzle of synchronic self-control. Agents are often most strongly motivated to do one particular thing - to A, rather than anything else. Must it be the case that, confronted with such motivation (and adding in the agent's belief that she is able to A), agents always A if they do anything intentionally at all? Many philosophers have argued against this so-called 'Law of Desire' (Davidson 1980). The puzzle, though, is explaining how this could be. Some argue that the agent is able to resist her strongest motivation via nonactional means (Kennett \& Smith 1996); some argue the agent can resist via ancillary actions (Mele 1997); still others argue the agent can resist directly (Sripada 2014). Among other reasons, these accounts are interesting because, in facing the puzzle, the philosopher must make theoretical decisions about the structure of the mind, and about the kinds of distance agents may be able to achieve from their strong motivational states.

These puzzles have to do with whether and how an agent acts in certain ways given background features: whether and how an agent acts contrary to a judgment about what is best, and whether and how an agent acts contrary to her strongest motivation at a time. The puzzle I wish to elucidate here involves halfheartedness in action: that is, an agent possesses weak overall motivation to A, but A-s intentionally nonetheless. And this generates a different kind of conflict. One might think of this as a conflict between an agent's commitment to executing her action and what an agent is motivated to accept regarding the execution of her action. Consider, for example, the following case.

Arezoo is performing a difficult dance routine at the end of a long day of practice. She knows that a part of this routine requires a significant amount of attentional control - that is, effortful concentration directed to certain parts of the action. She also knows she is suffering from weak motivation. Having performed under similar circumstances, Arezoo knows she is capable of concentrating harder than she currently is, and as the 
relevant dance part approaches, she knows that an effort at concentration would enable her to successfully execute the part, while maintaining her current level of concentration will impair performance. Due to her weak motivation, however, Arezoo does not make an effort at concentration. Consequently, although Arezoo intentionally performs the part, her execution of the part is very poor.

In virtue of the fact that she is intentionally performing the dance routine that includes the relevant part, and that she intends to perform the routine, Arezoo is committed to performing the dance part. And yet, Arezoo accepts poor performance of the part.

As with the puzzles of weakness of will and synchronic self-control, one might deny that this puzzle - we might call it a puzzle of knowingly halfhearted action - is possible. Perhaps, for example, Arezoo actually changes her intention in response to weak motivation. Perhaps she removes her commitment to performing the action. Or perhaps she downgrades her commitment somehow. (Perhaps it is possible to intend to A halfheartedly. ${ }^{8}$ ) Alternatively, perhaps Arezoo does not actually accept poor performance. Maybe she somehow deceives herself into thinking that she can perform appropriately in spite of not concentrating.

But suppose that the description I have offered is apt. If so, we are confronted with a bizarre case - a kind of agentive incoherence. For consider that when an agent intends an action, she commits to an action plan. The plan represents the steps to success in a somewhat idealized manner. Although agents are aware that mistakes or slippages in performance are common, neither mistakes nor slippages are a part of the intention. So while less than perfect execution of the plan may be acceptable in some sense, less than perfect execution represents a deviation from what is intended. ${ }^{9}$ Nonetheless, it seems that prima facie, agents

8. I could envision an account of the content of intentions such that intending to A halfheartedly is possible. Perhaps forming such an intention involves leaving various important parameters of the action vague, or involves weakly committing to the action plan. Spelling out and defending a viable option would take another paper, at least.

9. There might be good reasons to accept less than perfect execution. Two kinds of reasons come quickly to mind. First, an agent may need to conserve resources. Second, the effort required may, in some circumstances, be so aversive as to justify poor performance. In comments on an associated talk, Peter Railton raised a version of the following case, as did a referee.

As a parent of three and a successful lawyer, Arezoo often finds herself beset by a wide range of tasks. Recently she realized she needed to finish four separate tasks within a space of five minutes, just to get the children out the door and on the way to school. Arezoo believes she can do the tasks, but she hasn't had the chance to finish her (now cold) coffee, and she is quite tired. As a result she intends to finish all four tasks, but she could care less if, this morning, she performs these tasks well or not. Arezoo gets the tasks done, but poorly.

Arezoo may need to conserve resources for her day. Or it may be the case that she is so tired that expending the amount of effort required to perfectly execute her intention is simply too aver- 
should not knowingly accept less than perfect execution. To do so is to renege on the commitment embedded in the intention, while (bizarrely) continuing to hold that commitment in place.

There are different ways to confront this puzzle, either by explaining what happens in such cases of conflict, or by denying the possibility of such a conflict. My aim here is not to defend a particular response. There is not space for that. Rather, my aim is to support the more general contention that halfhearted action deserves philosophical reflection. For, as with the puzzles of weakness of will and synchronic self-control, confronting the present puzzle requires us to make theoretical choices regarding the structure of the mind, and in this particular case to say something about the relation between commitment and acceptance in action execution. In this connection, further questions - unaddressed hereinvolve the practical rationality of agents like Arezoo, ${ }^{10}$ as well as the moral responsibility agents like Arezoo might bear for similar actions in morally loaded contexts.

\section{Conclusion}

In this paper I have developed an account of halfheartedness with respect to action in terms of weak overall motivation to A. I have argued that claims about degrees of motivational strength should be understood as comparative claims with respect to well-constructed classes of comparison. And I have argued that motivational weakness should be understood by reference to a range of impacts upon the key functional roles of motivation for action. I do not claim to have discussed every key functional role in this paper; I focused on the functions of initiating, sustaining, and guiding action in order to demonstrate the plausibility of the account I offer. After setting out this general account, I defended an interesting upshot of it: when agents act halfheartedly they do so with impaired control over the action they execute. One reason this upshot is interesting is that in compromising control, halfhearted action sometimes generates a conflict within the agent between the agent's commitment in acting and what the agent is motivated to accept regarding her performance. I contrasted this conflict with related

sive. My response to this case, then, is the recognition of reasons that in some cases justify poor performance.

10. One might think of Arezoo's case as an example of a norm of practical rationality relating the intention of ends with the intention of means to successful performance. Just how to spell out the norm is not entirely clear from here, but consider the following comment due to Mark Schroeder: "Just as there is some interesting relationship between intending ends and intending means which are necessary to those ends, so also there is a more general connection between intending ends and intending non-necessary means that nevertheless facilitate those ends-which help to bring them about" (2009: 246). 
and better-known conflicts that arise in the literatures on weakness of will and self-control. As with reflection on weakness of will and self-control, further reflection on halfhearted action should enable better theories of the structure of human agency.

\section{Acknowledgments}

My thanks to two anonymous referees for comments, and to the editors at Ergo for doing such an excellent job with this journal and this paper. Thanks also to the lively, sharp audience at Bence Nanay's workshop on action and desire at the University of Antwerp, and to Al Mele, Myrto Mylopoulos, and Matt Parrott for discussion. This work was supported by Wellcome Trust investigator award [104347], and it contributes as well to the project 'Attentional Control and SelfControl,' funded by the John Templeton Foundation's initiative The Philosophy and Science of Self-Control.

\section{References}

Bench, Shane W. and Heather C. Lench (2013). On the Function of Boredom. Behavioral Sciences, 3(3), 459-472. https://doi.org/10.3390/bs3030459

Boksem, Maarten A. and Mattie Tops (2000). Mental Fatigue: Costs and Benefits. Brain Research Reviews, 59(1), 125-139. https://doi.org/10.1016/j.brainresrev.2008.07.001

Clarke, Randolph (1994). Doing What One Wants Less: A Reappraisal of the Law of Desire. Pacific Philosophical Quarterly, 75, 1-10.

Davidson, Donald (1980). Essays on Action and Events. Clarendon Press.

Eastwood, John D., Alexander Frischen, Mark J. Fenske, and Daniel Smilek (2012). The Unengaged Mind: Defining Boredom in Terms of Attention. Perspectives on Psychological Science, 7(5), 482-495. https://doi.org/10.1177/1745691612456044

Engelmann, Jan B. and Luiz Pessoa (2014). Motivation Sharpens Exogenous Spatial Attention. Motivation Science, I(S), 64-72. https://doi.org/10.1037/2333-8113.1.S.64

Frankfurt, Harry (1998). The Importance of What We Care About: Philosophical Essays. Cambridge University Press.

Gert, Joshua (2005). Breaking the Law of Desire. Erkenntnis, 62(3), 295-319. https://doi. org/10.1007/s10670-004-6881-1

Hare, Richard M. (1952). The Language of Morals. Clarendon Press.

Kanfer, Ruth, and Phillip L. Ackerman (1989). Motivation and Cognitive Abilities: An Integrative/Aptitude-Treatment Interaction Approach to Skill Acquisition. Journal of Applied Psychology, 74(4), 657-69o. https://doi.org/10.1037/0021-9010.74.4.657

Kennedy, Christopher (2004). Comparatives, Semantics of. In Keith Allen (Ed.), Encyclopedia of Language and Linguistics, $2^{\text {nd }}$ Edition. Elsevier.

Kennett, Jeanette and Michael Smith (1996). Frog and Toad Lose Control. Analysis, 56(2), 63-73. https://doi.org/10.1093/analys/56.2.63 
Kurzban, Robert, Angela Duckworth, Joseph W. Kable, and Justus Myers (2013). An Opportunity Cost Model of Subjective Effort and Task Performance. Behavioral and Brain Sciences, 36(6), 661-679. https://doi.org/10.1017/S0140525X12003196

McKitrick, Jennifer (2003). The Bare Metaphysical Possibility of Bare Dispositions. Philosophy and Phenomenological Research, 66(2), 349-369. https://doi. org/10.1111/j.1933-1592.2003.tb00265.x

McVay, Jennifer C., and Michael J. Kane (2009). Conducting the Train of Thought: Working Memory Capacity, Goal Neglect, and Mind Wandering in an Executive-Control Task. Journal of Experimental Psychology: Learning, Memory, and Cognition, 35(1), 196204. https://doi.org/10.1037/a0014104

McVay, Jennifer C., and Michael J. Kane (2012). Drifting from Slow to “D'oh!”: Working Memory Capacity and Mind Wandering Predict Extreme Reaction Times and Executive Control Errors. Journal of Experimental Psychology: Learning, Memory, and Cognition, 38(3), 525-549. https://doi.org/10.1037/a0025896

Mele, Alfred (1987). Irrationality. Oxford University Press.

Mele, Alfred (1997). Underestimating Self-Control: Kennett and Smith on Frog and Toad. Analysis, 57(2), 119-123. https://doi.org/10.1093/analys/57.2.119

Mele, Alfred (1998). Motivational Strength. Nô̂s, 32(1), 23-36. https://doi. org/10.1111/0029-4624.00085

Mele, Alfred (2003). Motivation and Agency. Oxford University Press. https://doi. org/10.1093/019515617x.001.0001

Mrazek, Michael D., Michael S. Franklin, Dawa Tarchin Phillips, Benjamin Baird, and Jonathan W. Schooler (2013). Mindfulness Training Improves Working Memory Capacity and GRE Performance While Reducing Mind Wandering. Psychological Science, 24(5), 776-781. https://doi.org/10.1177/0956797612459659

Prior, Elizabeth, Robert Pargetter, and Frank Jackson (1982). Three Theses about Dispositions. American Philosophical Quarterly, 19(3), 251-257.

Scarantino, Andrea and Michael Nielsen (2015). Voodoo Dolls and Angry Lions: How Emotions Explain Arational Actions. Philosophical Studies, 172(11), 2975-2998. https:// doi.org/10.1007/s11098-015-0452-y

Schroeder, Mark (2009). Means-End Coherence, Stringency, and Subjective Reasons. Philosophical Studies, 143(2), 223-248. https://doi.org/10.1007/s11098-008-9200-x

Schueler, George F. (1995). Desire: Its Role in Practical Reason and the Explanation of Action. MIT Press.

Shepherd, Joshua (2014). The Contours of Control. Philosophical Studies, 170(3), 395-411. https://doi.org/10.1007/s11098-013-0236-1

Smallwood, Jonathan, Emily Beach, Jonathan W. Schooler, and Todd C. Handy (2008). Going AWOL in the Brain: Mind Wandering Reduces Cortical Analysis of External Events. Journal of Cognitive Neuroscience, 20(3), 458-469. https://doi.org/10.1162/ jocn.2008.20037

Sripada, Chandra S. (2014). How is Willpower Possible? The Puzzle of Synchronic SelfControl and the Divided Mind. Nô̂s, 48(1), 41-74. https://doi.org/10.1111/j.14680068.2012.00870.x

Thalberg, Irving (1985). Questions about Motivational Strength. In Ernie LePore and Brian McLaughlin (Eds.), Actions and Events: Perspectives on the Philosophy of Donald Davidson (88-103). Basil Blackwell.

Tops, Mattie, and Maarten A. Boksem (2011). A Potential Role of the Inferior Frontal Gy- 
rus and Anterior Insula in Cognitive Control, Brain Rhythms, and Event-Related Potentials. Frontiers in Psychology, 2(330), 1-14. https://doi.org/10.3389/fpsyg.2011.00330

Tops, Mattie, Maarten A. Boksem, and Sander L. Koole (2013). Subjective Effort Derives from a Neurological Monitor of Performance Costs and Physiological Resources. Behavioral and Brain Sciences, 36(6), 703-704. https://doi.org/10.1017/S0140525X13001167

Vetter, Barbara (2014). Dispositions without Conditionals. Mind, 123(489), 129-156. https://doi.org/10.1093/mind/fzu032

Wei, Ping, Di Wang, and Ji Liyan (2015). Reward Expectation Regulates Brain Responses to Task-Relevant and Task-Irrelevant Emotional Words: ERP Evidence. Social Cognitive and Affective Neuroscience, 11(2), 191-203. https://doi.org/10.1093/scan/nsv097

Wulf, Gabriele, Charles Shea, and Rebecca Lewthwaite (2010). Motor Skill Learning and Performance: A Review of Influential Factors. Medical Education, 44(1), 75-84. https:// doi.org/10.1111/j.1365-2923.2009.03421.x 